\title{
Vocal Music Teaching Application Research based on Multimedia Technology in High Vocational Colleges
}

\author{
Wu Xiao \\ Henan Polytechnic University Jiaozuo, China, 463100 \\ $2446962948 @ q q . c o m$
}

Keywords: Multimedia technology; Vocal music teaching; Application

\begin{abstract}
With the rapid development of science and technology, multimedia technology is gradually widely used in the field of education, which is bound to vocal music teaching innovation and reform. The traditional single teaching mode and teaching tools of vocal music teaching in higher vocational colleges would be completely changed, and through the use of multimedia technology, vocal music teaching can be advanced to comprehensive teaching stage. This paper enumerates concrete application of multimedia technology in vocal music teaching, and discusses the utility of multimedia technology in vocal music teaching.
\end{abstract}

\section{Introduction}

Under the background of popularization and development of computer technology, arts higher vocational colleges have widely used multimedia technology in auxiliary impromptu accompaniment, harmony, solfeggio and ear training, music history and other course teaching. Comparing with traditional vocal music teaching, multimedia vocal music teaching has stronger superiority, which can effectively stimulate students' interest in learning, intuitively display complete teaching process, build beneficial effect on students correct voice ideas and create a new heaven and earth to vocal music classroom teaching.

\section{Traditional Vocal Music Teaching}

Traditional vocal music teaching is a feeling education. Vocal music teachers teach according to their feeling and experience, students sing by feeling, and many singing techniques and music expression are abstraction which are inexpressible. Language limitations of vocal music teaching and non-touch and visibility of vocal organs, etc. make vocal music art a music discipline both difficult and hard to teach. In view of this, quite a number of vocal music class teaching modes are one to one teaching, and it is mainly for singing and correct. Tradition vocal music teaching process is of the following two modules: the first module is student spend a lot of time to recite lyrics and read music before class; The second module is the teacher provides guidance for students in the classroom by using piano accompaniment in the process of singing. In summary, such teaching mode mainly exist the following disadvantages: first, the faculty team of higher vocational education is good and bad intermingled, which leads to the uneven level of accompaniment. In class, the teacher provides accompaniment singing to the student, which will certainly take teacher some energy, so it is difficult to concentrate and all hear students singing and provide guidance; the second is low efficiency. Because higher vocational colleges' students' knowledge mastering is relatively low, which leads to preferred reading music ability, and often can't remember the lyrics or ask for a lot of time. The last is to that it is hard for students to find singing feel in limited time in class. Higher vocational colleges teaching way is usually group lessons or collective lessons with limited teaching time. In addition, teachers use fuzzy and abstract vocal music teaching language, which leads to stop the students to point out problems and repeatedly correct, so as to let the students find the right singing sensation. Within a limited time, student voice and understanding differences and so on many problems make teachers unable to correct different students' different problems, and cannot keep students instant inspiration and good singers singing state. 


\section{Vocal Music Teaching Advantages with Multimedia Application}

Facing the problems of traditional vocal music teaching, widely use of multimedia technology rapid development is a perfect solution. Multimedia teaching, a kind of modern teaching means, has characteristics like highly informationization, visualization, visualization, and so on. Wide application of multimedia technology in vocal music teaching can eliminate the weakness of traditional teaching mode, fully mobilize students' enthusiasm, and improve vocal music teaching quality effectively. Based on the author's point of view, combining with long-term practice experience in music classroom teaching, the advantages of vocational vocal music teaching with proper use of digital teaching means are explored below.

One is to offer help to objective evaluate the students' sound ability. Different secondary education schools like vocational technical secondary school, vocational high schools, and ordinary high school are higher vocational colleges students sources. Students singing level and voice condition are different. Some students understanding of vocal music art is not enough, and lack of sound appreciation ability, and can't tell exactly what right voice is. Some even feel wrong voice is correct. Through the strengthening of training, these mistakes sound becomes subconscious habit, and need more energy to correct. Teachers in vocal music teaching process, through Cakewolk or Audition recording function, can solve this problem smoothly. With the aid of software, students can clearly hear their true voice, and find vocal music links errors in a timely manner, even can directly according to synchronous staff determine whether in place, intonation, sound wave shapes, sizes, identification of resonance and in this process see and hear the other students. Vocal music teaching teachers in higher vocational colleges through the use of computer software super multi-track recording function, record all students singing process, then pick out typical sounds to contrast, which can make students distinguish sound quality, find the existing problems, and recur to defect correction with the help of voice contrast. Analyze the entire recording sentence by sentence, repeatedly play and contrast strengths. Students frequently hear the best state, so they can grasp the best feel timely at a certain moment. Using this teaching method can better adapt to the practice of collective vocal music course in higher vocational colleges, and can even play twice the result with half the effort.

Second, it is to make students better vividly understand sound concept. Because in the study of vocal music, it is difficult to make students imitate the teacher sing using breath or open cavity. Use of breath is inside the body, and open cavity is to open the internal cavity. Just simply looking at the teachers' external expression is very difficult for students. In this process, we apply multimedia technology in vocal music teaching, through PowerPoint, simple animation courseware to demonstrate open cavity, and use of physical activity in the process of air condition. With the aid of animation image, students feel and understand more of body movement state and understand internal body parts working function. Gradually in-depth singing state of teachers in particular, with the aid of animation, is taught to students different tone cavity characteristics, explore the best sound position to provide the necessary help, seize moments of inspiration in vocal music practice link, and singing seems to be a strong memory. When the students practice to treble, the teacher must frequently make students demonstrate heavy gas. Although it is easy to say, it was really very difficult. In this process, the teacher can use camera to record students loud vocal state, continue to maintain students best vocal condition, let students watch over and over again, and timely analyze the comparative demonstration action correctly. Students can deeply feel voice cavity and contrast slight changes. According to recording data, students compare and contrast practice repeatedly. It is good for students to find correct sound state, memorize sing organ change, and get faster and stable state of singing.

Third is to correct articulation enunciation and efficiency improvement. While students sing The sun won't set in prairie, they often make mistake or have a too long rhyme "run" in the "the horse run below white clouds" lyrics. It is easy to let the words appear ambiguity, also it becomes "climb", so this would do great influence on incorrect music expression. And at this time, vocal music teachers, through recording software and the function of the instrument, amend the cartridge or waveform shaping to mark rhyme time points, compare waveform before and after to let the students choose 
between the two, so as to elevate students' subjective and objective perception. Compared with teacher repeated demonstration, this is relatively more convenient. In the song, "blue" in "white clouds floating in the blue sky" is L or N consonants, according to students recording comparison; it is easier to find the right pronunciation of this word.

Fourth is to help students have accurate sense of rhythm and intonation cultivation. From the reality, parts of vocal music students in higher vocational art colleges are of bad music sense. If they want a career in singing, one of the essential conditions is to have accurate rhythm and good intonation, which belongs to important contents of vocal music teaching, and can offer help to the students' better expression of a variety of genre music works. Under the influence of traditional teaching read music form, teachers can only use blackboard, chalk, piano in teaching, and the role of teacher is to check music play, sight singing accompaniment, dictation. The repetitive teaching forms have certain obstacles for students to form good accurate rhythm and intonation. In the process of vocal students, by Cakewolk Sonar software, make vocal music on the piano a MIDI file, supplemented by the effect of music and orchestra. Monotonous pure piano accompaniment will inevitably make a thorough change, so it can let students deeply appreciate music taste and understand artistic conception vocal part, and stir students' passion to sing in heart. And in this process, vocal music teachers does not need to make their own accompaniment, and can be completely liberated to direct students to utilize the breath and open cavity, put all his energy on listening for students to express music and sound condition, which would make students improve vocal effect, so as to lay a solid foundation for students singing.

Fifth is to let students cultivate good performance status. In vocal music teaching, singing posture plays a particularly important role. Students' posture during the process of singing has a direct relationship with cavity resonance, larynx location and respiratory status, vocal cords use, and the cooperation and coordination of all human vocal organs in voice process. The mental state and psychological state also can be decided in the process of singers in singing. While students are singing, frequent expression of contact stress and shoulder, foot, hand touch, head of violent shaking are all the important issues must be corrected in vocal music training. To solve these problems, use reference cameras. Through Capture Solution or video studio etc., simultaneously record students singing state. In order to more vividly let students find their deficiency, project it on the screen. Let the students copy each lesson video or make DVD for practice and watch. With the introduction of multimedia technology, we can save students sing process and visual image; let the students correct bad habits and incorrect singers sang posture to the greatest extent; and help the formation of students good performance status gradually.

Sixth is to offer help for students of vocal music works dealing ability and grasping various schools style. Because of higher vocational undergraduate art college students severely lack of vocal music theory and music theory knowledge, quite a proportion of the students just know national singing style, or with the help of teacher demonstration, know about various genres of art, and partly acquire knowledge with some fragments of sound recording or video recording or television. As a result, they have a vague impression on the knowledge, and have no systemic knowledge. A large number of audio and video data should be played for students to appreciate to let them create vivid, clear and systematic artistic image. Teachers in vocal music teaching process should take much more special tapes or VCD. By now, vocal music teachers' vocal teaching in higher vocational colleges can take network as convenient access to information, make full use of large capacity of information, carry wireless card, and connect to the Internet in the middle of vocal music teaching to let the students learn to appreciate. Introduce celebrity concert, excellent vocal music performance, and classical opera at home and abroad in formal occasions for reference. Teachers give specific interpretation of the work for students according to their respective shortcomings. By such a move, students can make more clear understanding of their own advantages and disadvantages, their efforts direction, and let students have more vocal music study interest, and improve vocal music singing ability gradually. 


\section{Conclusion}

Under the background of sustainable development of electronic information technology, the application of multimedia system and computer music certainly will bring higher vocational vocal music teaching innovation in teaching method, idea, method, content, etc. The application of multimedia technology in vocal music teaching can effectively improve the effectiveness of vocal music teaching. And in this process, it opens up a new path to let students actively learn vocal music. Literally, the application of multimedia technology in vocal music teaching research is absolutely not only the innovation of vocal music teaching tools, but the whole revolution of vocal music teaching and learning methods. Application of multimedia technology in vocal music teaching, of course, is still in exploration and research stage, which still needs to devote more resources to make multimedia technology gradually use in the service of modern vocal music teaching in vocational colleges.

\section{References}

[1] Yu Yanjie, Li Chengzhi. The application of multimedia and network technology in college vocal music teaching [J]. Journal of Harbin Polytechnic. 2011 (01) : 74-75

[2] Zhao Yutao, Hao Lei. vocal music teaching exploration under multimedia teaching environment [J]. Journal of Education and Profession. 2010 (15) : 122-123

[3] Liu Shiyin. The application of multimedia technology in college vocal music teaching [J]. Journal of Yancheng Normal University (Humanities and Social Science Edition), 2008 (03) : 111-113

[4] Sang Xiao. Stimulate interest in learning, optimize vocal music teaching [J]. Journal of Adult Education in China. 2009 (12) : 149-150 